\title{
Non-disruptive method to decrease stresses in the web of the crane beam
}

\author{
Alexander Danilov and Olga Tusnina* \\ Moscow State University of Civil Engineering, Yaroslavskoe shosse, 26, Moscow, 129337, Russia
}

\begin{abstract}
Ensuring the required resource of the bearing capacity of the crane beams is one of the most urgent tasks from the point of view of the rational design. The approach proposed in this article is based on the principle of redistribution of the functions of the elements involved in the operation of the crane structure. Weak resistance to rotation of the top flange and the adjoining web zone is a critical disadvantage of a typical crane structure. Additional reinforce elements are proposed to eliminate the consequences of the influence of this disadvantage. At the same time, these reinforce elements practically do not perceive either the vertical or horizontal components of the crane load, preventing only the rotation of the top flange on the length between the beam stiffeners. Another feature is that no additional stress concentration zones are created either in the flange or in the web from welding or drilling holes. The article provides a comparative analysis of the stress-strain state of the crane beams based on the results of numerical calculations carried out with the use of ABAQUS software package. It is shown that the stresses in the upper zone of the beam web, reinforced by the proposed method, are up to $20 \%$ lower than in a conventional I-beam. However, despite the simplicity of the solution, the positive results of numerical analysis and the supposed manufacturability of the approach, it is undoubtedly necessary to conduct a series of full-scale experiments on already existing objects.
\end{abstract}

\section{Introduction}

Crane beams are exposed to significant cyclic alternating loads from cranes. And one of the main problems is the correct choice of a design solution for the crane beams, which will minimize the effect of these unfavorable loads and factors on the stress-strain state of the beam and prevent its fatigue failure.

Well-known that the zone of the welds connecting the top flange with the web in the welded I-beams is the most problematic area. From these welds the formation of fatigue cracks in the web begins [1-3], since concentration of stresses arises in this zone, which is the main cause of fatigue failure [4].

The article [5] considers the bearing capacity of a crane beam of variable cross-section with a decrease in the height of the web to the supports. It is shown that in this case the

\footnotetext{
* Corresponding author: tsuninaoa@mgsu.ru
} 
most dangerous zones, where cracks appear, are the place of transition from the main section to the reduced one in the zone of connection of the web with the lower flange, at the place where the stress concentration appears.

The paper [6] analyzes the stress-strain state of crane girders during their normal operation in the absence of defects. It is shown that the stress-strain state of the web significantly depends on the eccentricity of the crane load, and that an inhomogeneous stress state arises along the web thickness, the degree of inhomogeneity of which also depends on the value of the eccentricity.

A large number of studies are devoted to the issue of reinforcement of the crane beams [7-9], as well as the analysis of the residual life of existing crane beams with cracks $[10,11]$ in order to predict the remaining service life of such beams.

In the article [12], the reinforcement of the crane girders by welding the angles to the top flange is considered, and it is argued that this method of strengthening increases the bearing capacity of the crane girder by 3-5 times in comparison with the original I-section. However, these results were obtained without considering fatigue failure and are intended only for light duty cranes.

Reinforcement of the top flange of hot-rolled beams to increase the rigidity of the beam from the plane of bending also increases the resistance of the section to torsion.

The article [13] considers the CFRP reinforcement of steel crane beams to increase their endurance.

In the paper [14] it was found that crane girders with a frictional connection of the top flange with the web have a higher service life in comparison with welded ones. Taking this into account, it is also proposed as an option to reinforce the existing crane beams using angles attached to the web and the top flange by high-strength bolts with controlled tension.

The article [15] presents a technique for repairing fatigue cracks in the lower stretched flanges of crane girders.

The problems of destruction of the fastening of crane rails are considered in the article [16].

There are a number of studies in which the method of calculating crane beams according to the Eurocode [1, 17] and American standards [18], including fatigue, is considered, and a comparison is made with experimental data. It is shown that in some cases the application of the normative method gives results that differ from the experimental data, which requires the clarification of theoretical calculations.

It should be noted that, in addition to crane girders, the construction of crane-secondary trusses also requires attention.

The article [19] considers the finite element analysis of crane-secondary truss as part of the frame of an industrial building. And in the paper [20] it is shown that the greatest number of defects and cracks in the lower chord of the crane-rafter truss occurs at the junction of the gussets with the top chord and in the zone of conjugation of the web with the top flange at the locations of the diaphragms.

Thus, increasing the endurance resource of crane structures is still one of the most urgent tasks from the point of view of both rational design of new crane girders and restoration of existing structures.

\section{Materials and methods}

The upper zone of the web is the most loaded place of the cross-section of the crane beam, which experiences alternating horizontal loads from the skew of the cranes, and from possible damage to the rail from the axis of the beam. As a result of these loads action the top flange is rotated with a part of the web around the longitudinal axis. In the welded beam, this area is also weakened by the weld. Therefore, to increase the resource of the 
crane beam, we should either get rid of the weld, or reduce the stress in it by some constructive measures.

While maintaining the weld as a connecting element between the flange and the web to increase the resource of the welded crane beam, it is possible to relieve the upper web zone from the influence of imperfections in the load transfer from the crane wheels and the horizontal component of the crane load. For this, the following constructive solution is proposed. Considering that under the action of the lateral load from the crane, the top flange rotates around its axis, involving the upper part of the web in this, it is necessary to prevent this rotation in some way. For this, it is proposed to ensure the support of the top flange on additional elements (for example, channel bars, I-beams, etc.). These elements are fixed on the stiffening ribs of the beam and prevent the flange from bending on the length between the stiffeners, which occurs due to imperfections in the transmission of the vertical and horizontal impact of the wheel. This article considers the option of reinforcing the flange with a channel (see fig. 1,b). The flange of the channel is tightly fitted to the top flange of the I-beam and is fixed to the stiffeners by welding or shear-resistant connection. For example, the channel can be attached to the intermediate and support ribs of the beam using high-strength bolts. The reinforcement element (in this case channel) is not attached to the beam flange. With such a solution, it is assumed that due to the tight fit of the channel to the I-beam flange, the section of the channel in its upper zone will perceive the pressure from the side of the I-beam flange and prevent its rotation around its axis. Thereby, the part of the alternating load from wheels, is basically removed from the problematic upper zone of the welded I-beam web. The transfer of force from the channel is carried out to the stiffeners of the crane beam, which redistribute this force through the vertical welds to a large lower part of the height of the beam web.

Thus, unloading of the problem zone of the crane beam web is achieved in the nearweld zone of its conjugation with the top flange of the girder.

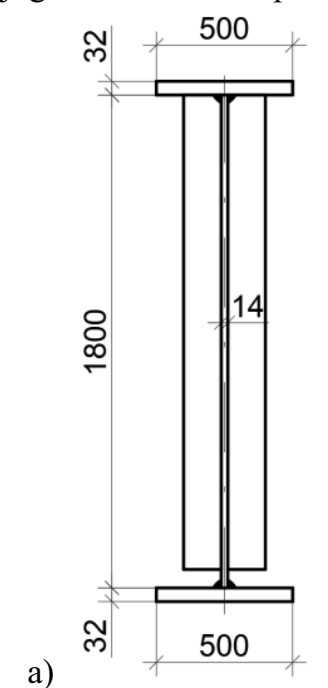

b)

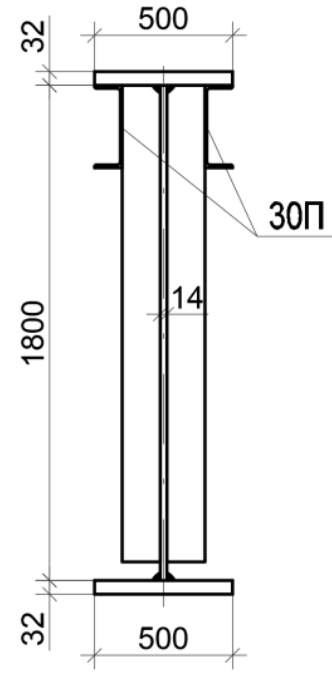

Fig. 1. Considered crane beam a) non-reinforced; b) reinforced

For a comparative analysis of the stress-strain state of a traditional crane I-beam and a beam reinforced with channels by proposed method, a numerical calculation was performed using the ABAQUS software package.

In the form of a numerical experiment, the calculation of a welded split beam with a span of $12 \mathrm{~m}$ for a crane with a lifting capacity of $200 \mathrm{t}$ was performed (the load from the crane wheel was taken equal to $50 \mathrm{t}$ ). Stiffeners with a section of $-140 \times 10$ are installed with 
a step of $1500 \mathrm{~mm}$ along the beam. Hot-rolled channels with the height of $300 \mathrm{~mm}$ was used as reinforcement elements.

A comparative analysis of the behavior of non-reinforced and reinforced crane beams has been performed (Fig. 1).

In the both cases (non-reinforced and reinforced), the horizontal rigidity of the crane structure was provided by the so-called "brake beam" (Fig. 2).

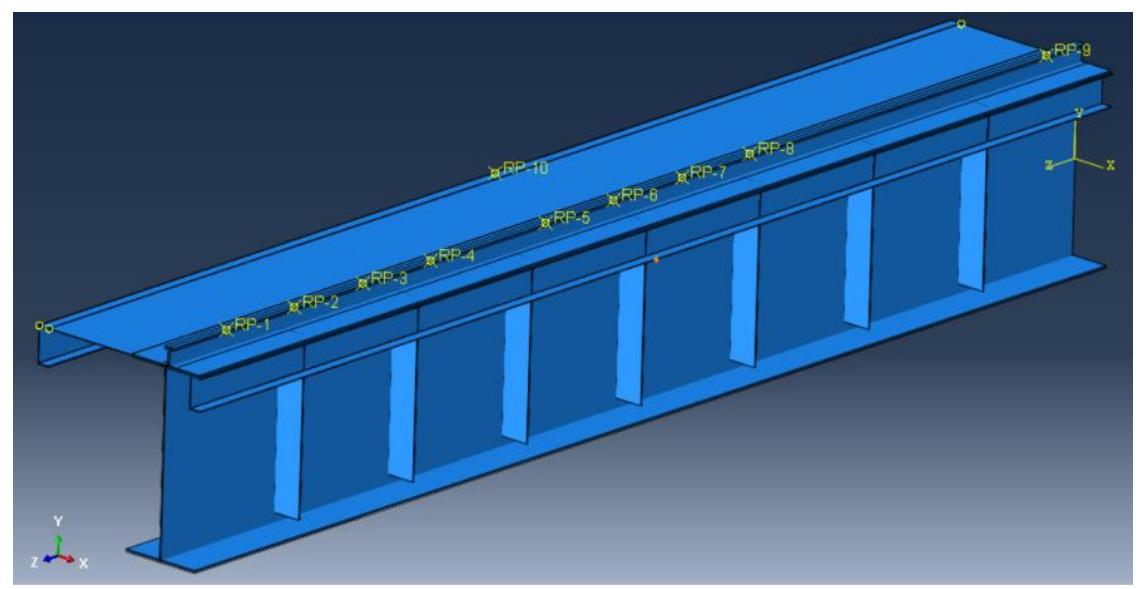

Fig. 2. Computer model of a reinforced crane beam (ABAQUS) - cross-section and along the axis

\section{Results}

The fig. 4 shows diagrams of normal and shear stresses along the web of reinforced and non-reinforced beam.

The marking of the positions along the web is lined from bottom to top - see Fig. 3.

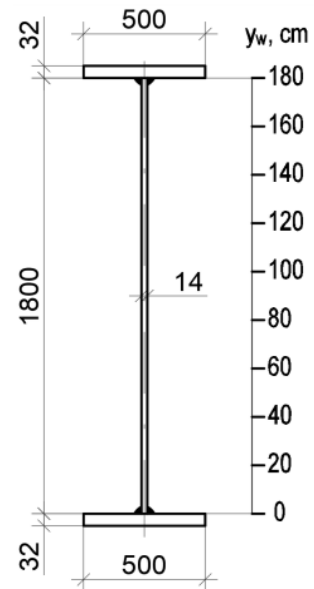

Fig. 3. The positions along the web height of the considered beam 

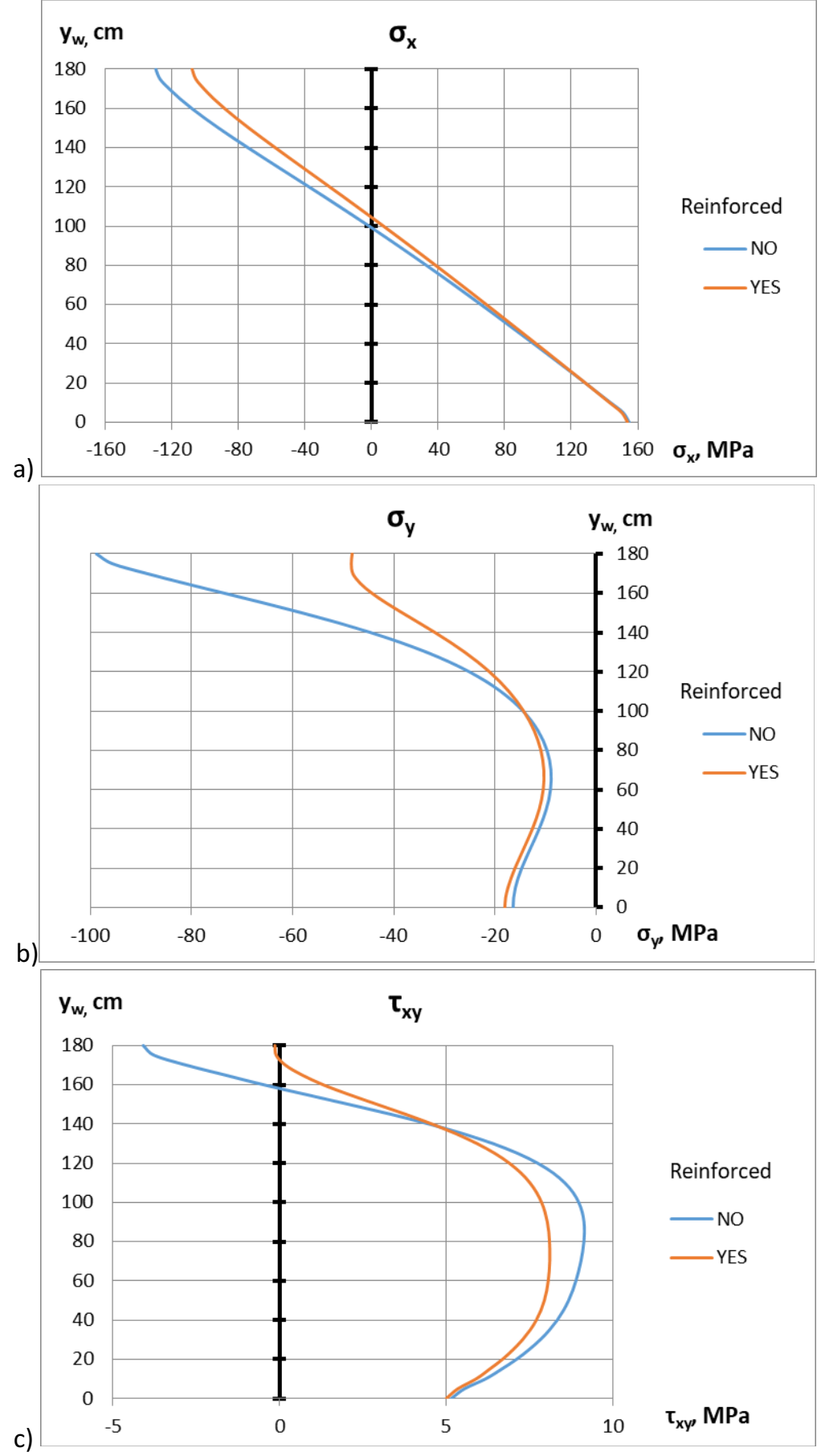

Fig. 4. The diagrams of stresses in the web of the beam a) normal stress $\sigma_{\mathrm{x}}, \mathrm{MPa} ; \mathrm{b}$ ) normal stress $\sigma_{\mathrm{y}}, \mathrm{MPa}$; c) shear stress $\tau_{\mathrm{xy}}, \mathrm{MPa}$

As can be seen in the diagrams, the stresses in the web of the reinforced beam are less than in the non-reinforced beam. 
In accordance with clause 12.1.2 SP 16.13330.2017 (rev. 1, 2) "Steel structures", fatigue calculation is performed using the formula:

$$
\frac{\sigma_{\max }}{\alpha R_{v} \gamma_{v}} \leq 1
$$

where $\sigma_{\max }$-the maximum absolute value of stress in the considered section of the element, calculated over the net section; $\alpha$ - the coefficient taking into account the number of loading cycles $n ; R_{v}$ - the calculated fatigue resistance; $\gamma_{v}$ - the coefficient that depends on the stress state and the stress asymmetry coefficient.

In this case $\sigma_{\max }$ is taken as the maximum von Mises stress in the upper compressed zone of the web.

The welded crane girder can be attributed to the $4^{\text {th }}$ group of structures according to App. K of SP 16.13330.2017. In this case the coefficient $\alpha$ is determined by the following formula:

$$
\alpha=0.07\left(\mathrm{n} / 10^{6}\right)^{2}-0.64\left(n / 10^{6}\right)+2.2
$$

For the $4^{\text {th }}$ group of structures, according to table. 35 , the design fatigue resistance $\mathrm{R}_{\mathrm{v}}=$ $75 \mathrm{MPa}$.

Taking into account the possible alternating action of the load from the crane skew, as well as the possible eccentricity of the rail in different directions from the beam web, we take $\gamma_{\mathrm{v}}=1$.

Table 1 shows the values of von Mises stresses in the upper compressed zone of the web, as well as the number of cycles that the beam can withstand from the condition of ensuring its fatigue strength, according to formula (1).

Diagrams of changes of the von Mises stresses in the beam web are shown in Fig. 5.

\begin{tabular}{|c|c|c|c|c|c|c|c|c|}
\hline \multirow{3}{*}{ Position } & \multicolumn{2}{|c|}{$\sigma_{\text {mis }}, \mathrm{MPa}$} & $\begin{array}{l}\text { Comparison } \\
\text { of stresses }\end{array}$ & \multicolumn{2}{|c|}{$\alpha$} & \multicolumn{2}{|c|}{$\begin{array}{c}\text { Number of cycles } \\
\mathrm{n} \cdot 10^{6}\end{array}$} & $\begin{array}{l}\text { Comparison } \\
\text { of the number } \\
\text { of cycles }\end{array}$ \\
\hline & \multicolumn{2}{|c|}{ Reinforced } & \multirow{2}{*}{$\begin{array}{l}\text { Reinforced } \\
\text { NO/YES }\end{array}$} & \multicolumn{2}{|c|}{ Reinforced } & \multicolumn{2}{|c|}{ Reinforced } & \multirow{2}{*}{$\begin{array}{l}\text { Reinforced } \\
\text { NO/YES }\end{array}$} \\
\hline & $\mathrm{NO}$ & YES & & NO & YES & $\mathrm{NO}$ & YES & \\
\hline 140 & 65.3 & 50.9 & $22 \%$ & 0.871 & 0.679 & 3.192 & 3.900 & $18.2 \%$ \\
\hline 145 & 73.0 & 57.5 & $21 \%$ & 0.973 & 0.767 & 2.735 & 3.900 & $29.9 \%$ \\
\hline 150 & 80.7 & 64.1 & $21 \%$ & 1.075 & 0.855 & 2.373 & 3.222 & $26.4 \%$ \\
\hline 155 & 88.2 & 70.5 & $20 \%$ & 1.177 & 0.940 & 2.067 & 2.871 & $28.0 \%$ \\
\hline 160 & 95.6 & 76.6 & $20 \%$ & 1.275 & 1.021 & 1.8 & 2.557 & $29.6 \%$ \\
\hline 165 & 102.6 & 82.3 & $20 \%$ & 1.369 & 1.097 & 1.568 & 2.304 & $31.9 \%$ \\
\hline 170 & 109.1 & 87.3 & $20 \%$ & 1.455 & 1.164 & 1.368 & 2.102 & $34.9 \%$ \\
\hline 175 & 114.9 & 91.7 & $20 \%$ & 1.532 & 1.222 & 1.201 & 1.940 & $38.1 \%$ \\
\hline 180 & 117.6 & 93.7 & $20 \%$ & 1.568 & 1.249 & 1.127 & 1.869 & $39.7 \%$ \\
\hline
\end{tabular}

Table 1. Comparison of the reinforced and non-reinforced beam 


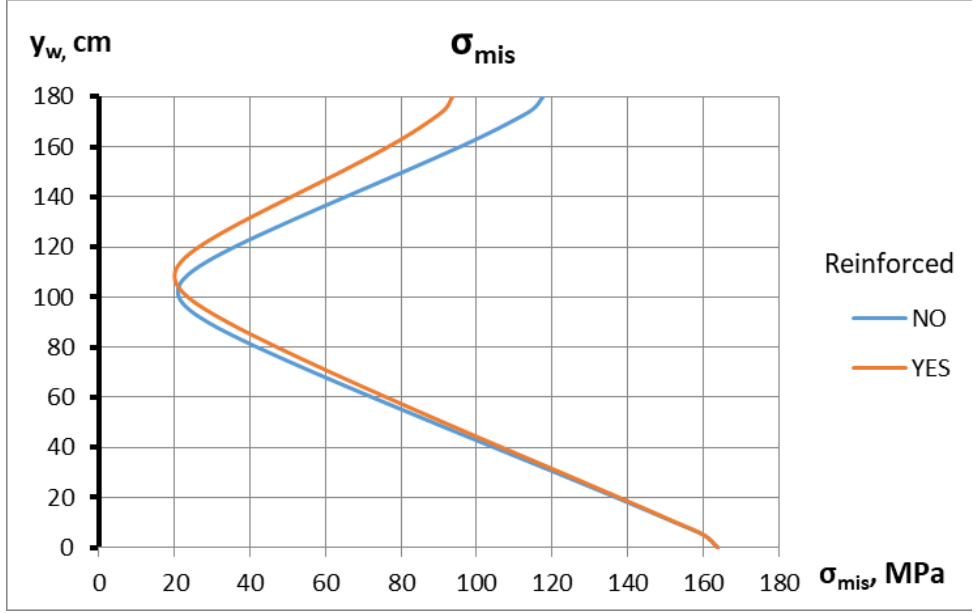

Fig. 5. The diagram of Mises stresses in the web of the beam

As can be seen from the table 1 and fig. 5 - von Mises stresses in the upper zone of the beam web with a reinforced top flange is $20 \%$ lower than in the non-reinforced beam. At the same time, when using the methodology of Russian standards for calculating the fatigue of crane beams, it was found that the resource of a reinforced by proposed method crane girder is almost $40 \%$ higher than that of a traditional welded I-beam.

\section{Discussion}

It should be noted that various methods of reinforcing existing crane beams are proposed: using steel reinforcement elements [12], CFRP [13], or by changing the constructive scheme of the crane beams [14].

However, they all have both their advantages and disadvantages, and in each individual case, it is necessary to analyze which of the reinforcing methods will be the most effective.

As another option for strengthening the crane girder, this article considers the reinforcement of the top flange with channels.

The proposed approach is based on the principle of redistribution of the functions of the elements involved in the operation of the beam. So, for example, the braking structure provides horizontal rigidity of the upper part of the crane structure, but is not able to provide sufficient resistance to the top flange of the beam with the adjacent part of the web to its rotation around the longitudinal axis.

Additional elements are designed just to eliminate the consequences of the influence of this disadvantage of a typical crane structure. At the same time, they practically do not perceive either vertical or horizontal components of the crane load, preventing only the rotation of the top flange.

Despite the positive results of numerical modeling, it is undoubtedly necessary to carry out a series of full-scale experiments on already existing facilities.

\section{Conclusions}

Based on the research carried out, the following conclusions can be made:

- to increase the resource of welded crane beams, it seems expedient to unload the upper web zone from bending out of its plane; 
- reinforcement of the top flange with a channel according to the proposed option (see Fig. $1, \mathrm{~b}$ ) allows to reduce the von Mises stresses in the upper zone of the web up to $20 \%$ (see Table 1);

- when applying the methodology of Russian standard SP 16.13330.2017 "Steel structures" to determine the number of cycles that the beam can withstand, it was found that the beam reinforced according to the proposed type withstands almost $40 \%$ more cycles compared to the non-reinforced welded I-beam;

- implementation of the proposed type of reinforcement is possible for both newly designed and existing beams;

- the results obtained are preliminary, experimental studies are required to carry out refinements.

\section{References}

1. S. Citarelli, M. Feldmann Fatigue failure of runway beams due to wheel loads, in Proceedings of the 14th Nordic Steel Construction Conference, 18-20 September 2019, Copenhagen, Denmark (2019)

2. J. Wardenier, P. de Vries, G. Timmermann Steel Const. 10, 67-71 (2017)

3. K. Rykaluk, K. Marcinczak, S. Rowiński Arch. Civ. Mech. Eng. 18, 69-82 (2018)

4. G.J. Xia The Structure of Steel 25 (4), 65-68 (2010)

5. Y. Xie Sensors and Transducers 21, 73-77 (2013)

6. V.V. Moskvichev, E.A. Chaban J. of Siberian Federal University. Eng. \& Tech. 9 (4), 572-84 (2016)

7. F.B. Cao, H.G. Wei, Z.H. Cheng Appl. Mech. and Mater 351-352, 1364-67 (2013)

8. A. Shuryn, A. Mukhin, A. Bryantsev E3S Web of Conference 212, 02016 (2020)

9. L.L. Yu, L. Xu 2012 Appl. Mech. and Mater. 166-169, 359-362 (2012)

10. V.V. Moskvichev, E.A. Chaban Industrial laboratory. Diagnostics of materials 84 (7), 47-54 (2018)

11. V.V. Moskvichev, E.A. Chaban Modern Tech. Syst Analysis. Modeling 58 (2), 8-18 (2018)

12. S. Movaghati Strengthening beam sections of industrial buildings against lateral torsional buckling, in Proceedings of the Annual Stability Conference Structural Stability Research Council, 2-5 April 2019, St. Louis, Missouri (2019)

13. Y. Yang Y, Q. Yue, L. Lian, J. He, X. Xia Appl. Mech. and Mater. 256-259, 986-990 (2012)

14. V.F. Takki, I.F. Egorov, O.A. Tusnina, Ind. Civ. Eng. 12, 61-67 (2020)

15. H. Kuwamura, M. Hanzawa J. Struct. Eng. 113 (11), (1987)

16. P. Kossakowski, W. Wcislik, M. Bakalarz MATEC Web of Conference 284, 09001 (2019)

17. G. Gremza G, J. Zamorowski J. Civ. Eng. Env. Arch. (JCEEA) 62, 135-148 (2015)

18. J.M. Fisher, J.P. Van de Pas Eng. J. 39, 65-73 (2002)

19. O.A. Tusnina 2018 Mag. Civ. Eng. 77, 68-89 (2018)

20. K.I. Yeremin. S.N. Shulga Ind. Civ. Eng. 4, 34-36 (2013) 